\title{
BMJ Open Interrupted time series analyses to assess the impact of alcohol control policy on socioeconomic inequalities in mortality in Lithuania: a study protocol
}

\author{
Jakob Manthey (D) , ,2,3 Domantas Jasilionis, ${ }^{4,5}$ Huan Jiang,,${ }^{6,7}$ \\ Olga Meščeriakova-Veliulienė, ${ }^{8}$ Janina Petkevičienè, ${ }^{9,10}$ Ričardas Radišauskas, ${ }^{11,12}$ \\ Jürgen Rehm, ${ }^{1,2,6,7,13,14}$ Mindaugas Štelemėkas ${ }^{9,10}$
}

To cite: Manthey J, Jasilionis D, Jiang $\mathrm{H}$, et al. Interrupted time series analyses to assess the impact of alcohol control policy on socioeconomic inequalities in mortality in Lithuania: a study protocol. BMJ Open 2021;11:e053497. doi:10.1136/ bmjopen-2021-053497

- Prepublication history for this paper is available online. To view these files, please visit the journal online (http://dx.doi org/10.1136/bmjopen-2021 053497).

Received 18 May 2021 Accepted 14 0ctober 2021
Check for updates

(C) Author(s) (or their employer(s)) 2021. Re-use permitted under CC BY-NC. No commercial re-use. See rights and permissions. Published by BMJ.

For numbered affiliations see end of article.

Correspondence to Dr Jakob Manthey; j.manthey@uke.de

\section{ABSTRACT}

Introduction Alcohol use is a major risk factor for mortality. Previous studies suggest that the alcoholattributable mortality burden is higher in lower socioeconomic strata. This project will test the hypothesis that the 2017 increase of alcohol excise taxes linked to lower all-cause mortality rates in previous analyses will reduce socioeconomic mortality inequalities.

Methods and analysis Data on all causes of deaths will be obtained from Statistics Lithuania. Record linkage will be implemented using personal identifiers combining data from (1) the 2011 whole-population census, (2) death records between 1 March 2011 (census date) and 31 December 2019, and (3) emigration records, for individuals aged $40-70$ years. The analyses will be performed separately for all-cause and for alcohol-attributable deaths. Monthly age-standardised mortality rates will be calculated by sex, education and three measures of socioeconomic status (SES). Inequalities in mortality will be assessed using absolute and relative indicators between low and high SES groups. We will perform interrupted time series analyses, and test the impact of the 2017 rise in alcohol excise taxation using generalised additive mixed models. In these models, we will control for secular trends for economic development.

Ethics and dissemination This work is part of project grant 1R01AA028224-01 by the National Institute on Alcohol Abuse and Alcoholism. It has been granted research ethics approval 050/2020 by Centre for Addiction and Mental Health Research Ethics Board on 17 April 2020, renewed on 30 March 2021. The time series of mortality inequalities as well as the statistical code will be made publicly available, allowing other researchers to adapt the proposed method to other jurisdictions.

\section{INTRODUCTION}

Health inequalities have been internationally recognised as a major public health problem which persists even in rather egalitarian highincome countries in the North of Europe. ${ }^{1}$ National and international policies have indicated the importance of health inequalities and proposing strategies towards reducing
Strengths and limitations of this study

- Census-linked mortality data will cover the entire population of Lithuania aged 40-70 years

- Mortality inequalities in Lithuania between 2011 and 2019 will be described using three different definitions of socioeconomic groupings (education, occupation, residence).

- An important limitation of census-linked studies is that the socioeconomic grouping is fixed at the census baseline.

- Interpretation of the association of alcohol control policy and mortality inequalities will depend on controlling for time-varying confounders.

inequalities. ${ }^{23}$ Furthermore, reducing health inequalities by combatting health burden in the disadvantaged population groups is one of the key preconditions for sustainable improvement of health and social welfare at the national level, and for overall increasing healthy life expectancy. ${ }^{45}$

Health inequalities are most commonly frequently defined by mortality and life expectancy differences between groups with low and high socioeconomic status (SES). For example, a study based on people aged 25 years from 18 In countries of the Organization for Economic Co-operation and Development (OECD) the population with low levels of education had on average a shorter life expectancy as compared with their counterparts with high levels of education (life expectancy gap among women: $2.5-8.3$ years; among men: $4.1-13.9$ years) ${ }^{6}$

Indicators of health inequality are commonly classified as either absolute or relative measures. Range-type absolute indicators describe the absolute difference in the outcome of interest between two groups, such as in the example of life expectancy 
by educational achievement outlined above or absolute difference in age-standardised death rates. Rangetype relative indicators compare the ratios in health outcomes. There are also more complex regression-based or Gini-type measures of health inequalities accounting for mortality rates across all SES groups and taking into account the size of each group. For a diverse set of both relative and absolute indicators of health inequalities used, see Ref. 7.

To understand European trends in health inequalities, it needs to be considered that all-cause mortality rates generally decreased in the past decades. In many Eastern European countries, however, mortality rates increased in the 1990s and this trend only reversed in the 2000s. The declining mortality trends were observed for all SES groups, but the degree of improvement differed across different groups, resulting in a mixed picture of trends in health inequalities. ${ }^{78}$ For example, substantial reductions of absolute health inequalities were observed in many European countries between 1990 and 2012, whereas in relative terms, the picture was mixed. ${ }^{7}$ Importantly, in times of declining mortality rates, absolute health inequalities can narrow even if percentage reductions in mortality rates in high SES groups are greater than those in low SES groups, because the absolute reductions in deaths among high SES may still be lower. In contrast, relative health inequalities can only narrow if the percentage reductions in mortality are more pronounced in low SES groups and this currently does not happen in most countries.

To further understand the trajectories of health inequalities in Europe, country-specific and diseasespecific trends as well as economic developments need to be considered. For example, there were also substantial variations in mortality trends by SES across different countries between 2000 and 2011. A comparative study examining trends in mortality by SES groups in 15 European countries found that mortality from alcohol-related causes of death has declined more strongly among low SES as compared with high SES men in Hungary, while the opposite was observed in Poland in the same period. ${ }^{5}$ Among women, achievements in smoking-related causes of deaths were more pronounced among high as compared with low SES groups in many countries, contributing to unfavourable trends in health inequalities. The same study also reports that rising income inequality was associated with more pronounced mortality increases among men and thus contributed to widening of health inequalities. Moreover, health expenditure was a driver for narrowing health inequalities, acting via amenable causes of death. ${ }^{7}$ Lastly, in populations with higher rates of high educational achievements and lower rates of loweducated people, mortality inequalities were larger, thus, widening health inequalities. ${ }^{9}$

To further understand differential trends in health outcomes between SES groups, differences in risk taking behaviours, such as smoking, physical inactivity and alcohol use need to be considered. ${ }^{10} \mathrm{~A}$ recent study estimated that up to $27 \%$ of mortality inequalities could be explained by alcohol use. In Eastern European countries, where levels of alcohol consumption have been among the highest globally, ${ }^{11}$ alcohol-related inequalities are among the highest in Europe, explaining up to $10 \%$ of total mortality inequalities.

Lithuania has been identified as one of the European countries with high levels of both health inequalities and alcohol consumption. ${ }^{712}$ Studies show that mortality rates have substantially increased between 1990-1994 and 2005-2009 among low-educated persons, contrasting decreasing trends in mortality among low-educated persons from 10 other European locations. ${ }^{13}$ Comparing data from 2001 and 2014, both absolute and relative mortality gaps between low-educated and high-educated persons were found to have widened in Lithuania. ${ }^{14}$ In this period, the socioeconomic difference in all-cause mortality rates increased among men and women by about one-third. A more refined set of analyses using data of life expectancy at age 30 between 2001 and 2014 identified breaking points in the trajectories of health inequalities in Lithuania. ${ }^{15}$ The results suggest that lower educated males did not show any improvements, while life expectancy among higher educated men increased starting in 2006, suggesting a widening of health inequalities between 2006 and 2014. For women, a similar pattern was observed.

Health inequalities in Lithuania were not only studied with regards to educational differences but also by economic activity status and occupation. ${ }^{16-19}$ For example, it has been shown that substantial relative mortality disadvantage of unemployed and economically inactive people aged 30-64 years increased between 2001-2005 and 2011-2015. ${ }^{17}$ The same study reports that despite some overall decline in the total amount of inequality (across all economic activity groups), the rate difference between the unemployed and employed groups slightly increased further. Moreover, the internationally highest absolute mortality differentials by occupation have been recorded in Lithuania. ${ }^{18} 19$ This unfavourable situation is attributable to very high mortality among people with unskilled manual and farmers/farm labourer occupations. Finally, numerous studies point to a long-term persistence of significant excess mortality among rural residents constituting about one third of the population in 2020. ${ }^{20} 21$ The most significant relative excess rural mortality was observed for external causes of death and cardiovascular system diseases. $^{21}$

As outlined above, alcohol use is an important contributor to health inequalities in Eastern Europe, which has also been confirmed for Lithuania. ${ }^{22}$ Data for 2011-2015 show that deaths from alcohol-attributable diseases were 4.6 times more likely among low-educated persons, as compared with the high-educated counterparts. ${ }^{23}$ This contrasts to 2.1 times higher all-cause mortality rates among low versus high-educated Lithuanians in this period. Given the high levels of per capita consumption and alcohol-attributable disease burden, ${ }^{11}{ }^{12}{ }^{24}$ alcohol is likely to be a key driver for health inequalities in Lithuania. 
Since 2008, a number of effective alcohol policies have been enacted in Lithuania, ranging from bans on advertising, increasing drink-driving penalties, reducing the availability of alcohol by banning sales at petrol stations or restricting sales hours, and increasing taxes for alcoholic beverages. ${ }^{25}$ Using time series analyses, the implementation of alcohol policies have been linked to a reduction in alcohol-attributable motor vehicle accidents and injuries, ${ }^{26}$ as well as to declines in all-cause mortality. ${ }^{27}$ The most robust evidence for reduction in mortality has converged for an increase in alcohol excise taxes $(111 \%-$ $112 \%$ for wines and beer; $23 \%$ for ethyl alcohol relating to spirits), implemented on 1 March 2017. 2528

While the evidence for reducing overall harm through alcohol control policies is strong, studies on their impact on health inequalities are sparse. Following microeconomic theories, it can be hypothesised that the impact of price increases on purchasing behaviour will be greater among people with less disposable income, making taxation-based policies an appealing option to reduce health inequalities. ${ }^{29}$ Accordingly, raising the floor price of alcoholic beverages in Scotland has resulted in reductions in alcohol purchases among more deprived households. ${ }^{30}$

In this article, we present a study protocol for assessing (1) the trajectory of inequalities in mortality in Lithuania between 2011 and 2019 and and (2) the potential impact of the recently introduced increase in alcohol excise taxes in Lithuania on changes in the magnitude of absolute and relative mortality inequalities.

Based on the above considerations, the impact of the 2017 tax increase would preferably be evaluated using mortality rates for different income groups. As incomestratified mortality data are missing, the proposed study will use educational achievement as SES indicator, which has been used in previous analyses of health inequalities in Europe and also for Lithuania specifically. ${ }^{723}$ In sensitivity analyses, mortality inequalities based on alternative SES groupings (by occupation and place of residence) will be examined.

In sum, our study will not only shed light on the impact of a potential intervention to reduce mortality per se, but also to reduce inequalities in mortality. If our hypothesis can be confirmed, we will demonstrate the potential of raising excise taxation as an alcohol control policy to reduce mortality inequalities in a country and thereby make a contribution to improve people's quality of life.

\section{METHODS AND ANALYSIS \\ Study design and data source}

To test the hypothesis on declining health inequalities being linked to the 2017 tax increase, we will perform interrupted time series analyses using mortality data registered between March 2011 and December 2019. For this retrospective observational study, a control time series is not available. However, interrupted time series without controls constitute an adequate and commonly applied tool to evaluate alcohol policies, ${ }^{27} 31$ and the validity of the results is dependent on controlling for time-varying confounders, which will be addressed in this study. ${ }^{32} 33$

The target population will be the population aged 40-70 participating in the 2011 census in Lithuania. The lower age threshold reflects the fact that we only have data from people aged 30 and older in the censuslinked mortality dataset and following up this population for almost a decade would imply that the age group 30 to 39 years old would become smaller with every month into the study period. In order to avoid introducing a bias in the analyses, we will include only age groups for which data are available for the entire study period. The upper age threshold is based on the rationale to study mortality inequalities in the population of working age with the most pronounced alcohol consumption and experiencing the highest rates of alcohol-attributable health losses. ${ }^{11}{ }^{24}$ We will exclude people immigrating to Lithuania after the census as no SES information is available for this population. Excluding immigrants is a standard procedure in census-linked mortality studies and the annual immigration rate ranged between 5.2 (2011) and 14.3 (2019) per 1000 population ${ }^{34}$; thus, the contribution of immigrants to mortality inequalities is expected to be negligible.

Linking census data with death records, the target population will be followed up for a total of 106 months, from March 2011 to December 2019. The census-linked mortality data include information on sex, date of birth, educational attainment at census, economic activity, occupation, date of death, cause of death (4 digit code according to the International Statistical Classification of Diseases and Related Health Problems, 10th Revision [ICD-10]), place of residence (urban, rural) and emigration details (status and date of emigration). Information on emigration is needed to calculate person months of exposure.

For calculating monthly age-standardised mortality rates, a breakup of the number of deaths (numerator) and person months (denominator) for each sex-age-SES group and for each month will be calculated. For the numerator, the number of deaths can be directly calculated. For the denominator, we will calculate the average yearly person months and obtain monthly estimates by first dividing the yearly estimates by 12 and second linearly interpolating between years. Persons emigrating from Lithuania and not returning until the end of the observational period will be included into the calculations of person months of exposure until the emigration date. Persons immigrating to Lithuania after the census are excluded from the analyses as detailed above. As the assignment of persons to age groups will change over time, the allocation of numerator and denominator to the correct age bands will be required. We will use the 'age-of-death' format as described by Mackenbach et $a l^{35}$ that is, allocating deaths and person-years to the current age band. For person years, this will represent the longest period of the year at a specific age (eg, 61 if the person 
turned 61 in February, or 42 if the person turned 43 in October).

To account for differences in age structure within sociodemopraphic groupings, we will calculate monthly sexstratified and SES-stratified age-standardised mortality rates, using the midpoint of the study period as standard population.

\section{Defining dependent variables}

As dependent variables, we will calculate absolute and relative indicators of mortality inequalities. Specifically, this will be (1) the absolute difference in age-standardised mortality rates between low and high SES groups, and (2) the ratio of age-standardised mortality rates between low and high SES groups.

There will be two sets of dependent variables, defined by diagnostic grouping: (1) all-cause mortality, (2) an indicator for alcohol-attributable diseases (ICD-10 diagnostic codes: K70, K74, X45, T51, F10, G31.2, G62.1, I42.6, K29.2, K86.0, K85.2). For liver disease, we use the wider categories of $\mathrm{K} 70$ and $\mathrm{K} 74$, as there had been several coding rule changes for K70 in Lithuania during the time period examined. The combined indicator may result in a more consistent indicator even though not all of the cases in K74 category are alcohol attributable.

The definition of SES groups will be based on a threelevel educational attainment recorded at the 2011 census, as this is the most time-invariant SES measure available. In line with the definition of the International Standard Classification of Education (ISCED), the highest educational attainment will be grouped into the following categories:

- ISCED 0-3 (low educational achievement): upper secondary school, gymnasium; vocational school after graduating from an upper secondary school; vocational school after graduating from a lower second school and acquired an upper secondary education together with a profession; vocational school after graduating from a lower secondary school; vocational school without completion of a lower secondary school and acquired a lower secondary education together with a profession; vocational school without completion of a lower secondary school; special secondary school; a lower secondary school; (unfinished) primary school; literate (no schooling); illiterate; unknown.

- ISCED 4 (middle educational achievement): professional college; special secondary school.

- ISCED 5-8 (high educational achievement): doctoral studies; university; college.

We will conduct sensitivity analyses to assess whether the results are robust to the SES grouping. The following two alternative SES groupings will be employed: first, for manual versus non-manual and other workers (restricted to the population employed at time of census and defined using the 2008 International Standard Classification of Occupations ${ }^{36}$ ), and second, for the urban versus rural population.
Thus, there will be 12 dependent variables in total: 2 mortality inequality indicators (absolute and relative) for 2 mortality groupings (all-cause and alcohol) and 3 different sociodemographic groupings (education, occupational status, urban-rural).

\section{Statistical analyses and model selection criteria}

To test the hypothesis, we will perform various generalised additive mixed models (following recommendations of Beard et a ${ }^{33}$ : previous applications on Lithuanian mortality data $\left.{ }^{26-28}\right)$. For each time series, the mortality inequality indicators are expected to be normally distributed, which will be tested using QQ-plots. For models using dependent variables following other distributions, we will adjust the link function to adjust the model to the respective distributional family (eg, log link function for Poisson distributed values).

In all models, seasonality will be accounted for using smoothing splines. To correct autocorrelation, autoregressive and/or moving average terms will be included in the models. To identify the correct order of autoregressive or moving average terms and to identify whether autocorrelation remains in the time series, we will use the auto. arima function in $\mathrm{R}$, inspect (p)ACF plots and perform Ljung-Box tests using a threshold of $\mathrm{p}=0.05$. Lastly, the residuals in all models will be checked for stationarity using augmented Dickey-Fuller tests (threshold of $\mathrm{p}=0.05$ ) and visual inspection of residuals in the time series. If more than one candidate model results in a stationary time series without autocorrelation, we will conduct likelihood ratio tests to identify the model with best model fit. If no difference in model fit can be assessed, we will prefer the simplest model, that is, that with fewer variables.

\section{Control variables}

To control for time-varying confounding that could explain changes in the dependent variable, we will consider the following control variables:

- A secular trend variable (linear, quadratic, cubic).

- Quarterly data on gross-domestic product, linearly imputated to monthly estimates (Statistics Lithuania).

- Unemployment rates by educational achievement according to ISCED 2011 definition (Eurostat, online data code: LFSQ_URGAED).

- Income distribution (annual data from the EU-SILC survey and to be obtained from Eurostat):

- a) the sex-specific ratio of disposable income received by the $20 \%$ of the population with the highest income (top quintile) to that received by the $20 \%$ of the population with the lowest income (lowest quintile; online data code: ILC_DI11).

- b) the Gini coefficient, defined as deviation from a completely equal income distribution across the population, with 0 marking complete income equality and one marking complete income inequality (online data code: ILC_DI12).

- c) the sex-specific share at risk for poverty (cutoff defined as $60 \%$ of median equivalised income 
after social transfers), by educational achievement according to ISCED 2011 definition (online data code: ILC_LI07).

- Health expenditure (Eurostat, online data code: TPS00207).

- Educational expansion, defined as the proportion of population in highest educational group according to ISCED 2011 definition (Eurostat, online data code: EDAT_LFS 9903).

Annual covariate data will be fixed at July in each year and monthly values will be imputed by linear imputation.

\section{Main analysis}

In the main analysis, we will first build baseline models with (a selection of) control variables (see above) using the time series up until the policy implementation month (March 2011 to February 2017, n=72 months). The selection of covariates in the baseline models will be determined by the aims of (1) removing autocorrelation and (2) achieving stationarity (see above for the tests required). These baseline models will be used to build the final models by (1) extending the time series to the whole study period and (2) including those variables that test for an immediate level change and for a slope change in the dependent variable. The level change will be tested using a binary variable for examining the 2017 policy, coded ' 0 ' in all months prior to March 2017 and ' 1 ' in all months March 2017 onwards, assuming an abrupt and persistent level change in the dependent variable. The slope change will be tested using a variable coded ' 0 ' in all months prior to March 2017 and then increasing by 1 with every additional month.

\section{Additional analyses}

While the primary aim of this study will be to evaluate the 2017 taxation increase, it should be considered that, between 2014 and 2019, a range of other 'best buy' alcohol control policies deemed to be effective in reducing alcohol-attributable harm were implemented (see table 1). ${ }^{25}$ As any effect of the 2017 tax increase could be confounded by effects of other policies enacted in close temporal proximity, we will conduct further analyses aiming to identify associations between any alcohol control policy implementation and changes in health inequalities.

Two types of additional analyses inspired by previous evaluations of alcohol control policies in Lithuania will be performed.$^{26}$ In the first set of additional analyses, we will evaluate the cumulative link between the implementation of alcohol control policies and health inequalities. In the second set of additional analyses, we will compare the observed trends in health inequalities in the period without any alcohol control policy implemented (March 2011 to March 2014) to the period of various alcohol control policies implemented (April 2014 to December 2019). Specifically, we would expect a lower slope in the latter period as compared with the former (eg, less steep increase or more pronounced decrease).
Table 1 . Description and expected impact of effective alcohol control policies enacted in Lithuania between 2011 and 2019

\begin{tabular}{|c|c|c|}
\hline $\begin{array}{l}\text { Date of policy } \\
\text { implementation }\end{array}$ & Description of policy/policies & $\begin{array}{l}\text { Policy } \\
\text { weight }\end{array}$ \\
\hline 1 April 2014 & $\begin{array}{l}\text { Taxation/price } \\
\text { (increase excise tax by } 10 \%- \\
47 \% \text {; and } 1 \% \text { for ethyl alcohol) }\end{array}$ & 0.5 \\
\hline 1 March 2015 & $\begin{array}{l}\text { Taxation/price } \\
\text { (increase in excise tax of } \\
10 \%-16 \% \text { for beer, wine, and } \\
\text { intermediate products; and } 2 \% \\
\text { for ethyl alcohol) }\end{array}$ & 0.5 \\
\hline 1 January 2016 & $\begin{array}{l}\text { Availability } \\
\text { (sales banned at petrol } \\
\text { stations) }\end{array}$ & 0.5 \\
\hline 1 March 2017 & $\begin{array}{l}\text { Taxation/price } \\
\text { (increase in excise tax of } \\
111 \%-112 \% \text { for wine, beer, } \\
\text { and intermediate products; } \\
\text { and } 23 \% \text { for ethyl alcohol) }\end{array}$ & 1 \\
\hline 1 January 2018 & $\begin{array}{l}\text { 1. Availability (increase in } \\
\text { legal minimum age and in } \\
\text { enforcement; and reduced } \\
\text { off-premise sales hours) } \\
\text { 2. Marketing/advertisement } \\
\text { (full ban of TV, radio, and } \\
\text { internet advertisements } \\
\text { with few exceptions) }\end{array}$ & 0.5 \\
\hline
\end{tabular}

Parts of the table content is taken from Rehm et al. ${ }^{25}$

For the first set of additional analyses, the cumulative link between the implementation of alcohol control policies and health inequalities will be defined by a variable that takes the value 0 prior to the first policy implemented (March 2011 to March 2014) and then increases with every policy implemented. The increase for each set of policies is weighted by their expected impact as detailed in table 1 . As for the 2017 tax increase, a decline in affordability of alcoholic beverages was identified, which is believed to be a driver for reducing health inequalities, we will assign a weight of 1 for this policy. All other policies are expected to have similar effects and will be assigned a weight of 0.5 .

For the second set of additional analyses, the two different periods will be defined by two variables that increase by 1 with every additional month in their period and take on the value 0 outside of their period. Thus, the first period will be coded 1-37 between March 2011 and March 2014 and the second period will be coded 1-69 between April 2014 and December 2019.

As outlined above, the main analysis will involve building baseline models first before adding the covariate of interest. For the additional analyses, a different modelling strategy will be required because the covariates of interest are expected to have an impact for the entire time series, with unforeseeable implications for autocorrelation and stationarity (in contrast to the main analyses, where the 
baseline time series is restricted to the time prior to the implementation of the policy of interest). Instead, several candidate models with the covariate of interest will be built. The candidate models will differ with respect to the combination of covariates, in particular indicators of economic wealth (gross-domestic product), deprivation (unemployment rates, poverty), income inequality and educational expansion. Among those candidate models that are free from autocorrelation and made the time series stationary, we will select the final model based on the same criteria as described for the main analysis.

\section{Expected outcomes}

From the proposed models in the main analyses, we will obtain the changes in level and slope of mortality inequalities associated with the 2017 alcohol tax increase. Depending on the outcome and the results, this could be expressed in various ways, such as: (1) the absolute reduction in the mortality rate difference between groups with low and high educational achievements that was observed in March 2017 (for the level change in the absolute mortality inequality indicator); (2) the monthly reduction in the mortality rate ratio between groups with low and high educational achievements that occurred in March 2017 and the following months (for the slope change in the relative mortality inequality indicator).

For all measures, 95\% CIs will be obtained from the models and reported.

\section{Patient and public involvement}

Patients and the public were not involved in conceptualising the proposed study.

\section{ETHICS AND DISSEMINATION}

The proposed analyses will be carried out as part of a larger project on evaluating alcohol control policies in Lithuania funded by the National Institute on Alcohol Abuse and Alcoholism (NIAA) (grant no. 1R01AA028224-01). The project has undergone formal ethical review from the Research Ethics Board of the Centre for Addiction and Mental Health (CAMH REB), Toronto, Canada (REB decision letter no. 050/2020). Further, the Lithuanian Bioethics Committee has confirmed that handling of individual-level census and mortality data is not subject to the requirements of the Law on the Ethics of Biomedical Research in Lithuania (certificate no. 6B-17-91).

The census-linked mortality data will be obtained from Statistics Lithuania. All procedures involving individual record linkages were performed at Statistics Lithuania following the rules of data confidentiality and by employees having permission to work with confidential data. For the purpose of the proposed study, individuallevel anonymised data are aggregated to calculate monthly age-standardised mortality rates. These mortality rates will constitute the base for the statistical analyses outlined in this study protocol and will not allow to identify natural persons.
As with previous studies of the above mentioned project, ${ }^{27}$ the underlying aggregated time series of mortality inequalities and the statistical code will be published together with the results. This will facilitate further analyses of the same data and the adaptation of the proposed methods to other data.

\section{DISCUSSION}

It has been recognised that health inequalities serve as major barrier for both the future health improvements and social development. ${ }^{37}$ While the contribution of lifestyle risk factors, such as smoking and alcohol use, to health inequalities are well known, ${ }^{10} 38$ the evidence base of alcohol and smoking control policies to reduce these health inequalities remains scarce.

High levels of alcohol consumption and a comparably large attributable disease burden globally ${ }^{24}$ and particularly in Europe $^{12}$ require effective public health interventions, such as increasing the retail price of alcoholic beverages. ${ }^{31}{ }^{39}$ The more than $100 \%$ excise tax increase for beer and wine implemented in March 2017 in Lithuania has been linked to a reduction of all-cause mortality. ${ }^{27}$ Extending the evaluation of this and other alcohol control policies to health inequalities, as proposed in this study, is key to assess possible unintended negative consequences, such as widening the gap between people with low and high SES. As such, it will be one of the first studies using empirical data to evaluate the impact of alcohol control policies on health inequalities (modelling studies ${ }^{2940}$ ).

This study will also serve as benchmark for additional studies on health inequalities in Lithuania and elsewhere. Being embedded in a multicountry project to evaluate alcohol policies in Lithuania and other Baltic countries, we expect this study to influence further applications, for example, to evaluate other alcohol control policies, ${ }^{41}$ to make age-specific analyses, or to use other outcomes, such as hospitalizations.

This study has several strengths. First, we use censuslinked mortality data covering the entire national population of Lithuania. Census linkage of death records is one of the few possibilities to study the socioeconomic variation in mortality in a given country. As such data remain scarce in the Central and Eastern European region, our study will provide important insights also for neighbouring countries. Second, the study will use both relative and absolute indicators of socioeconomic inequalities in mortality, thus, providing a complete assessment of mortality inequalities in Lithuania. ${ }^{8}$ Third, we will test our assumptions using three different measures of socioeconomic position, allowing for a more comprehensive measure of mortality inequalities in Lithuania and the possible impact of alcohol control policies. Lastly, the data will provide an update to the trajectories of mortality inequalities in Lithuania, which used to be among the largest in Europe. ${ }^{7}$

One of the main limitations of this study is inherent to evaluating effects of public health policies. As these 
policies are usually not implemented under controlled and randomised conditions, establishing causality for policy effects constitutes a real challenge. Using interrupted time series analyses, an internal control is build from previous observations, which makes this technique one of the most robust methods to evaluate policy interventions. ${ }^{32}$ Acknowledging that the robustness of findings from interrupted time series analyses is heavily depending on controlling for possible confounders, in particular, time-varying confounders, we will attempt to rule out alternative explanations. For this purpose, we will include several contextual variables such as indicators of poverty, income inequality, educational expansion and health expenditure, which are expected to be linked to health inequalities. If, as postulated, the 2017 taxation increase has attenuated health inequalities, this should be largely independent of variations in these confounders. In other words, accounting for known drivers of health inequalities, we will strengthen the internal validity of the results.

Moreover, the results will be interpreted in line with other effective alcohol control policies implemented in Lithuania in close proximity to the 2017 increase of alcohol excise taxation, including sales restrictions in petrol stations, restrictions of opening hours, ban of advertisements and increasing the minimum legal drinking age. ${ }^{25}$ The proposed additional analyses will allow us to examine the association of alcohol control policies and mortality inequalities from a broader perspective.

In conclusion, the results of this study will not only provide an update on the trajectories of mortality inequalities in Lithuania but also offer valuable insights on the link of alcohol control policy and health inequalities. The study findings will be compared against assumptions and estimates from previous modelling studies and are expected to strengthen the evidence base regarding the real-world effectiveness of alcohol control policies.

\section{Author affiliations}

${ }^{1}$ Institute of Clinical Psychology and Psychotherapy, Technische Universität Dresden, Dresden, Germany

${ }^{2}$ Center for Interdisciplinary Addiction Research (ZIS), Department of Psychiatry and Psychotherapy, University Medical Center Hamburg-Eppendorf (UKE), Hamburg, Germany

${ }^{3}$ Department of Psychiatry, Medical Faculty, University of Leipzig, Leipzig, Germany ${ }^{4}$ Laboratory of Demographic Data, Max- Planck- Institute for Demographic Research, Rostock, Germany

${ }^{5}$ Demographic Research Centre, University of Leipzig, Vytautas Magnus University, Kaunas, Lithuania

${ }^{6}$ Institute for Mental Health Policy Research, Centre for Addiction and Mental Health, Toronto, Ontario, Canada

${ }^{7}$ Dalla Lana School of Public Health and Department of Psychiatry, University of Toronto, Toronto, Ontario, Canada

${ }^{8}$ Department of Health Management, Faculty of Public Health, Lithuanian University of Health Sciences, Kaunas, Lithuania

${ }^{9}$ Health Research Institute, Lithuanian University of Health Sciences, Kaunas, Lithuania

${ }^{10}$ Department of Preventive Medicine, Faculty of Public Health, Lithuanian University of Health Sciences, Kaunas, Lithuania

${ }^{11}$ Department of Environmental and Occupational Medicine, Lithuanian University of Health Sciences, Kaunas, Lithuania

${ }^{12}$ Institute of Cardiology, Lithuanian University of Health Sciences, Kaunas, Lithuania
${ }^{13}$ Campbell Family Mental Health Research Institute, Centre for Addiction and Mental Health, Toronto, Ontario, Canada

${ }^{14}$ Department of International Health Projects, Institute for Leadership and Health Management, I.M. Sechenov First Moscow State Medical University, Moscow, Russian Federation

\section{Twitter Jakob Manthey @JakobManthey}

Contributors JM: conceptualisation, funding acquisition, methodology, project administration, writing - original draft preparation, writing - review \& editing. DJ, $\mathrm{HJ}, \mathrm{OM}-\mathrm{V}, \mathrm{JP}$, and RR: conceptualisation, methodology, writing - review \& editing. JR and MS: conceptualisation, funding acquisition, methodology, writing - review \& editing. The first author accepts full responsibility for the conduct of the study and controlled the decision to publish.

Funding This work was supported by the US-based National Institute of Alcohol Abuse and Alcoholism, grant number 1R01AA028224-01.

\section{Competing interests None declared.}

Patient and public involvement Patients and/or the public were not involved in the design, or conduct, or reporting, or dissemination plans of this research.

Patient consent for publication Not applicable.

Provenance and peer review Not commissioned; externally peer reviewed.

Open access This is an open access article distributed in accordance with the Creative Commons Attribution Non Commercial (CC BY-NC 4.0) license, which permits others to distribute, remix, adapt, build upon this work non-commercially, and license their derivative works on different terms, provided the original work is properly cited, appropriate credit is given, any changes made indicated, and the use is non-commercial. See: http://creativecommons.org/licenses/by-nc/4.0/.

ORCID iD

Jakob Manthey http://orcid.org/0000-0003-1231-3760

\section{REFERENCES}

1 Mackenbach JP. Nordic paradox, southern miracle, eastern disaster: persistence of inequalities in mortality in Europe. Eur J Public Health 2017;27:14-17.

2 European Commission. Communication from the Commission to the European Parliament, the Council, the European Economic and Social Committee and the Committee of the Regions - Solidarity in health: reducing health inequalities in the EU 20097 April 2021. Available: https://ec.europa.eu/health/social_determinants/policy/ commission_communication_en

3 Commission of the European Communities. Together for health: a strategic approach for the EU 2008-2013, 2007. Available: http:// www.europeanpublichealth.com/wp-content/uploads/2016/01/EUHealth-Strategy-Together-for-Health.pdf

4 Marmot M. The health gap: the challenge of an unequal world. London: Bloomsbury, 2015.

5 Sen A. Inequality Reexamined. Oxford, UK: Oxford University Press, 1995.

6 Murtin F, Mackenbach JP, Jasilionis D. Educational inequalities in longevity in 18 OECD countries. J Demogr Economics 2021;2:1-29.

7 Mackenbach JP, Rubio Valverde J, Bopp M, et al. Progress against inequalities in mortality: register-based study of 15 European countries between 1990 and 2015. Eur J Epidemiol 2019;34:1131-42.

8 Mackenbach JP. Re-thinking health inequalities. Eur J Public Health 2020;30:615.

9 Östergren O, Lundberg O, Artnik B, et al. Educational expansion and inequalities in mortality-A fixed-effects analysis using longitudinal data from 18 European populations. PLoS One 2017;12:e0182526.

10 Stringhini S, Carmeli C, Jokela M, et al. Socioeconomic status and the $25 \times 25$ risk factors as determinants of premature mortality: a multicohort study and meta-analysis of 1.7 million men and women. The Lancet 2017;389:1229-37.

11 Manthey J, Shield KD, Rylett M, et al. Global alcohol exposure between 1990 and 2017 and forecasts until 2030: a modelling study. Lancet 2019;393:2493-502.

12 World Health Organization. Status report on alcohol consumption, harm and policy responses in 30 European countries 2019. Moscow: WHO European Office for the Prevention and Control of Noncommunicable Diseases, 2019. http://www.euro.who.int/en/ health-topics/disease-prevention/alcohol-use/publications/2019/ 
status-report-on-alcohol-consumption,-harm-and-policy-responsesin-30-european-countries-2019

13 Mackenbach JP, Kulhánová I, Artnik B, et al. Changes in mortality inequalities over two decades: register based study of European countries. BMJ 2016;353:i1732.

14 Mesceriakova-Veliuliene O, Kalediene R, Sauliune S. Changes in inequalities of mortality by education level in Lithuania between 2001 and 2014. Public Health 2020;182:88-94

15 Mesceriakova-Veliuliene O, Kalediene R, Sauliune S, et al. Inequalities in life expectancy by education and its changes in Lithuania during 2001-2014. Medicina 2021;57. doi:10.3390/ medicina57030245. [Epub ahead of print: 05 Mar 2021].

16 Kalediene R, Prochorskas R, Sauliune S. Socio-Economic mortality inequalities in Lithuania during 2001-2009: the record linkage study. Public Health 2015;129:1645-51.

17 Jasilionis D, Stankūnienè V, Baublytè M. Changes in socioeconomic mortality inequalities at adult and old ages in Lithuania, 2001-05 to 2011-15. Eur J Public Health 2019;29:971-3.

18 Toch-Marquardt M, Menvielle G, Eikemo TA, et al. Occupational class inequalities in all-cause and cause-specific mortality among middleaged men in 14 European populations during the early 2000s. PLoS One 2014;9:e108072.

19 Tanaka H, Nusselder WJ, Bopp M, et al. Mortality inequalities by occupational class among men in Japan, South Korea and eight European countries: a national register-based study, 1990-2015. J Epidemiol Community Health 2019;73:750-8.

20 Kalediene R, Petrauskiene J. Socio-Economic transition, inequality, and mortality in Lithuania. Econ Hum Biol 2004;2:87-95.

21 Mesceriakova-Veliuliene $\mathrm{O}$, Kalediene R. Changes in mortality inequalities in urban and rural populations during 1990-2018: Lithuanian experience. Medicina 2021;57:750.

22 Mackenbach JP, Valverde JR, Bopp M, et al. Determinants of inequalities in life expectancy: an international comparative study of eight risk factors. Lancet Public Health 2019;4:e529-37.

23 Pechholdová $\mathrm{M}$, Jasilionis $\mathrm{D}$. Contrasts in alcohol-related mortality in Czechia and Lithuania: analysis of time trends and educational differences. Drug Alcohol Rev 2020;39:846-56.

24 Shield K, Manthey J, Rylett M, et al. National, regional, and global burdens of disease from 2000 to 2016 attributable to alcohol use: a comparative risk assessment study. Lancet Public Health 2020;5:e51-61.

25 Rehm J, Štelemėkas M, Ferreira-Borges C, et al. Classifying alcohol control policies with respect to expected changes in consumption and Alcohol-Attributable harm: the example of Lithuania, 2000-2019. Int J Environ Res Public Health 2021;18:2419.

26 Rehm J, Manthey J, Lange S, et al. Alcohol control policy and changes in alcohol-related traffic harm. Addiction 2020;115:655-65.
27 Štelemėkas M, Manthey J, Badaras R, et al. Alcohol control policy measures and all-cause mortality in Lithuania: an interrupted timeseries analysis. Addiction 2021;116:2673-84.

28 Jiang H, Tran A, Gmel G, et al. How to quantify deaths averted derived from interrupted time-series analyses, 2021.

29 Meier PS, Holmes J, Angus C, et al. Estimated effects of different alcohol taxation and price policies on health inequalities: a mathematical modelling study. PLoS Med 2016;13:e1001963.

30 O'Donnell A, Anderson P, Jané-Llopis E, et al. Immediate impact of minimum unit pricing on alcohol purchases in Scotland: controlled interrupted time series analysis for 2015-18. BMJ 2019;366:I5274.

31 Wagenaar AC, Maldonado-Molina MM, Wagenaar BH. Effects of alcohol Tax increases on alcohol-related disease mortality in Alaska: time-series analyses from 1976 to 2004. Am J Public Health 2009;99:1464-70.

32 Bernal JL, Cummins S, Gasparrini A. Interrupted time series regression for the evaluation of public health interventions: a tutorial. Int J Epidemiol 2017;46:348-55.

33 Beard E, Marsden J, Brown J, et al. Understanding and using time series analyses in addiction research. Addiction 2019;114:1866-84.

34 Statistics Lithuania. Crude immigration rate 2021. Available: https:// osp.stat.gov.It/

35 Mackenbach JP, Menvielle G, Jasilionis D, et al. Measuring Educational Inequalities in Mortality Statistics. OECD Statistics Working Papers 2015/08 [Internet], 2015.

36 International Labor Organization. International standard classification of occupations ISCO-08. Geneva: International Labor Organization, 2012. https://www.ilo.org/global/publications/ilo-bookstore/orderonline/books/WCMS_172572/lang-en/index.htm

37 United Nations. Sustainable development goals: good health and well-being, 2016. Available: https://sustainabledevelopment.un.org/ sdg3

38 Mackenbach JP, Bopp M, Deboosere P, et al. Determinants of the magnitude of socioeconomic inequalities in mortality: a study of 17 European countries. Health Place 2017;47:44-53.

39 Chisholm D, Moro D, Bertram M, et al. Are the "Best Buys" for Alcohol Control Still Valid? An Update on the Comparative CostEffectiveness of Alcohol Control Strategies at the Global Level. J Stud Alcohol Drugs 2018;79:514-22.

40 Jiang $\mathrm{H}$, Livingston $\mathrm{M}$, Room $\mathrm{R}$, et al. Modelling the effects of alcohol pricing policies on alcohol consumption in subpopulations in Australia. Addiction 2020;115:1038-49.

41 Tran $\mathrm{A}$, Jiang $\mathrm{H}$, Lange $\mathrm{S}$. The impact of increasing the minimum legal drinking age to 20 years in Lithuania on all-cause mortality - an interrupted time-series analysis. medRxiv 2021. 